\title{
Rock Destruction with Volumetric Compression
}

\author{
Gogolin Vyacheslav.A. \\ T.F. Gorbachev Kuzbass State Technical University \\ Kemerovo, Russian Federation \\ inna-e@inbox.ru
}

\begin{abstract}
The complete diagrams of rocks compression with deformation above compressive strength are considered. Strength properties of rocks at the volume compression are defined: compressive strength, residual strength, modulus of deformation above compressive strength. Physical relationships are used: failure criterion, the energy equation of the limit beyond deformation, and experimental laws. The theoretical values of the maximum rock strength comply with the experimental data. It is proposed to use the results for the forecast of rock pressure and the safety of mining. It is identified that the modulus of deformation above compressive strength equals modulus of deformation before reaching this limit.
\end{abstract}

Keywords - rocks compression, deformation above compressive strength, compressive resistance, residual strength, deformation module, rock destruction

\section{INTRODUCTION}

At the present time the importance of studies in the area of mechanical processes of rock destruction in coal mines and open pits significantly increases [1-4]. It is inspired by the trend of the growth of coal volume mined in Kuzbass (Western Siberia, Russia) [5-8], by public and Government focuses on the ecological safety of mining [9-12]. However, the key point of rock destruction - physical processes of this phenomenon - lacks scholars' attention. Nevertheless, in T.F. Gorbachev Kuzbass State Technical University some research was conducted in the area of modeling the fractured rocks $[13,14]$ by estimating the influence of mining expansion on industrial safety.

One of the areas ensuring safety of the underground mining is the effective management of rock pressure in order to maintain a steady state of mines, to prevent dynamic and other manifestations of rock pressure.

The estimation of the steady state of the rock mass in the areas of development and production operations is carried out on the basis of calculations of the rock stress-strain state using strength criteria.

The main characteristic of rock strength is the compressive strength in simple compression. In real situations rock mass is volumetric or in plain-strain deformed condition.

To determine rocks compressive strength in these states it was offered to use a strength criterion based on the concept of destruction mechanism of rocks and analysis of the available full diagrams of samples compression.

In testing rock samples for simple compression using hard pressure plants, several authors obtained diagrams of rock compression with the deformation above compressive strength (full compression diagrams with above deformation) [15-18].

Consideration of the above rock deformation allows us to describe the actual geo-mechanic state of the edges of the banks and pillars.

Also, behavior of rocks is used in the calculations of stress-strain state and stability of rocks in the production area and near the area of preparatory mining [19-22].

In these studies, we used the strength and deformation characteristics obtained in simple compression (compressive strength, modulus of recession, the retained strength).

In this paper, the theoretical values of deformation and strength characteristics of rock, being in a volume strength state above compressive strength are described.

\section{METHODS}

In this article, we used the methods of experimental data analysis to find a strength criterion. Volume strength of rocks is identified based on the linear - deformable medium law. Modulus of deformation is obtained by the adjustment of the energy of sublimit and above the limit deformation.

\section{RESULTS}

The main results of the research are the following.

1. The criterion of rock strength at volume compression is offered. The loss of rock strength in this state occurs at a certain value of transverse deformation. The amount of the limit value of the transverse deformation is determined by the results of rock samples tests in simple compression.

2. The condition that the accumulated deformation energy up to compressive strength equals the energy of above deformation is used. It is identified that the modulus of deformation above compressive strength equals the modulus of deformation before reaching this limit.

3. The compressive strength of rocks with a volume contraction and the residual strength are proportional to the cross-pressures.

\section{DISCUSSION}

The analysis of full diagrams of sidereal pressure boosting of rock samples has shown that under the pressure of 0.97 of compressive strength the value of lateral deformation remains stable (Fig. 1a). 

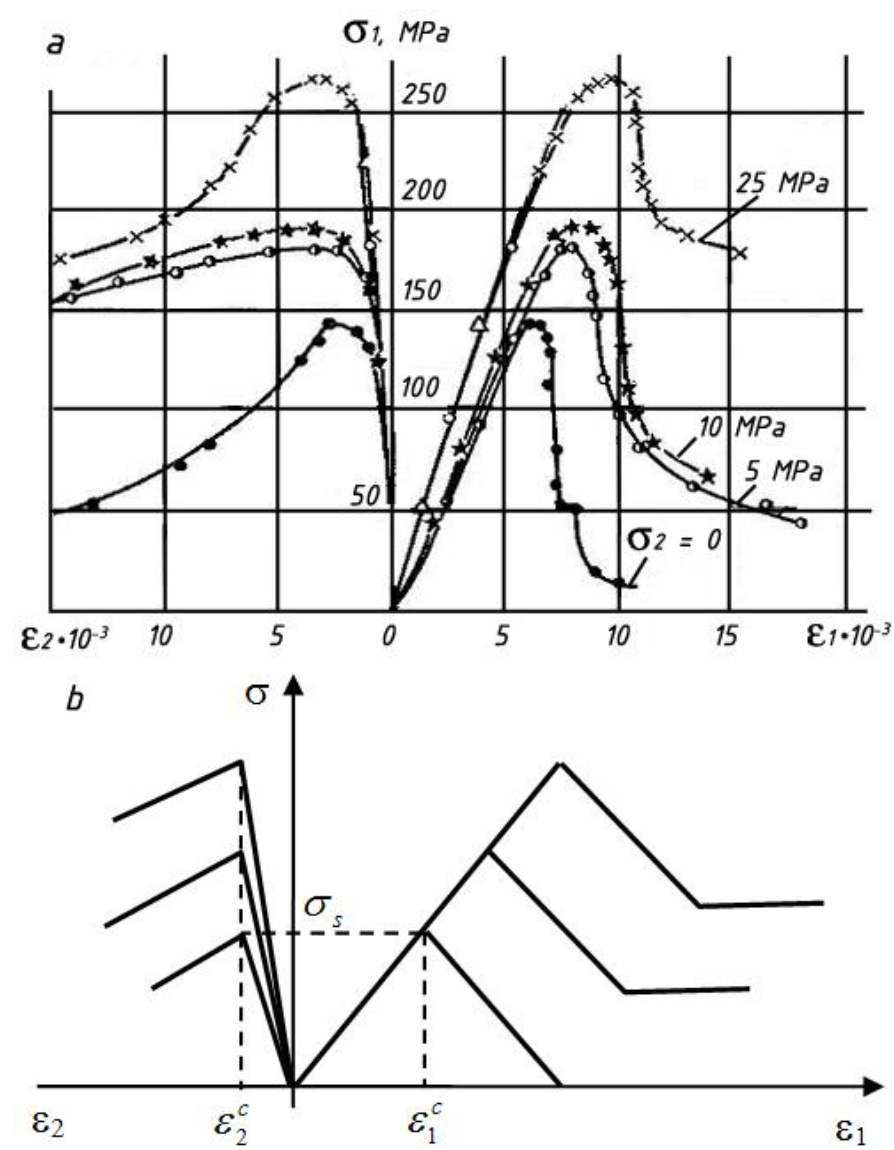

Figure 1. Full diagram of rock compression:

a) Donbass (Ukraine) sandstones; b) model of full diagram of compression

Under simple pressure with vertical intensity $\sigma 1$ up to compressive strength $\sigma$ s the rock sample is getting destroyed with the module E. Herewith its vertical deformation should be $\varepsilon_{1}=\sigma_{1} / E$. Moreover, the lateral deformation is defined by the module of lateral deformation $v$ and connected with vertical strain as $\varepsilon_{2}=-v \cdot \varepsilon_{1}=-v \sigma_{1} / E$. Here the compressing stress is accepted as positive and tension stress as negative provided that the tensions reach the maximum strength there are horizontal micro-splits appearing in the rock sample [18]. The consequence of this is the significant lateral deformation of the rock sample. The sample is losing its solids-carrying capacity and its farther above deforming is going on under load decrease.

Thus, the increase of lateral deformation up to the maximum strength $\varepsilon_{2}^{s}=-v \sigma_{s} / E$ can be used as criterion of simple compression resisting power.

The vertical strains in above the limit segment also depend on the tensions with the linear deformation module $\mathrm{M}$ (the module of decline). So the model diagram of triaxial compression can be designed as it has been shown in Fig. $1 \mathrm{~b}$.

The hypotheses of piecewise-linear approximation of compression full diagram was used in the calculations of rock stress-strain behavior, for example in [16]. However, in this study the values of compressive strength, residual strength and the decline module were accepted using experimental data.

Under the volumetric rock compression the lateral tension is $\sigma_{2}=\sigma_{3}=\sigma_{x}$, and according to Hooke's law the lateral deformation is $\varepsilon_{2}=\left[\sigma_{x}-v\left(\sigma_{1}+\sigma_{x}\right)\right] / E$. Using the lateral deformation $\varepsilon_{2}^{s}=-v \sigma_{s} / E$ as a criterion of volumetric compressive strength, we can calculate the volumetric compressive strength $\sigma_{s}^{v}$ as the following:

$$
\sigma_{s}^{v}=\frac{1-v}{v} \sigma_{x}+\sigma_{s}
$$

Comparison of the theoretical values of rock samples at compressing with laboratory tests data [17] is shown in the table where the stress is shown in megapascals. Unfortunately, it was impossible to make such a comparison with other data of laboratory tests [18], as in these works there is no information about the coefficients values of transverse deformations of test rocks.

Laboratory (lab.) and calculated (calc.) values of volumetric compressive strength of rocks are given in Table.

TABLE. LABORATORY AND CALCULATED VALUES THE VOLUMETRIC COMPRESSIVE STRENGTH OF ROCKS

\begin{tabular}{|c|c|c|c|c|c|c|}
\hline \multicolumn{7}{|c|}{ sandstone (Donbass, Ukraine ) } \\
\hline$\sigma_{2}$ & 0 & 5 & 10 & 25 & 50 & 100 \\
\hline$\varepsilon_{2}^{s}$ & 2,7 & 3,2 & 3,4 & 3,4 & 3,4 & 3,7 \\
\hline$\sigma_{2}^{s}$, lab. & 142 & 180 & 190 & 265 & 350 & 425 \\
\hline$\sigma_{1}^{s}$, calc. & 142 & 179 & 215 & 325 & 507 & 872 \\
\hline Deviation, \% & 0 & 0,8 & 13,2 & 22,5 & 44,9 & 105,2 \\
\hline \multicolumn{7}{|c|}{ Biotit granit (Karelya, Russia ) } \\
\hline$\sigma_{2}$ & 0,3 & 5 & 10 & 25 & 50 & 100 \\
\hline$\varepsilon_{2}^{s}$ & 2,4 & 2,6 & 2,6 & 2,4 & 7,5 & 7,6 \\
\hline$\sigma_{2}^{s}$, lab. & 164 & 214 & 231 & 280 & 435 & 598 \\
\hline$\sigma_{1}^{s}$, calc. & 164 & 189 & 213 & 289 & 409 & 654 \\
\hline Deviation, $\%$ & 0 & 11,9 & 7,8 & 3,2 & 6,0 & 9,4 \\
\hline \multicolumn{7}{|c|}{ Marble (Koelga, Russia) } \\
\hline$\sigma_{2}$ & 0 & 2,5 & 10 & 25 & 50 & 100 \\
\hline$\varepsilon_{2}^{s}$ & 4,6 & 4,4 & 4,3 & 4,0 & 5,0 & 6,0 \\
\hline$\sigma_{2}^{s}$, lab. & 57 & 95,2 & 115,5 & 145 & 185 & 234,5 \\
\hline$\sigma_{1}^{s}$, calc. & 57 & 68 & 102 & 171 & 285 & 513 \\
\hline Deviation, \% & 0 & 28,2 & 13,2 & 17,1 & 54 & 119 \\
\hline
\end{tabular}

The deviation error of theoretical values of rock strength in compression from the experimental data with the values of the lateral load up to $25 \mathrm{MPa}$ is less than $28.2 \%$. 
For rock in the state of simple deformation $\varepsilon_{3}=0$ and $\sigma_{3}=v\left(\sigma_{1}+\sigma_{2}\right)$. Then the lateral deformation considering equation for $\sigma 3$ has the following view:

$\varepsilon_{2}=\left[\sigma_{2}-v\left(\sigma_{1}+\sigma_{3}\right)\right] / E=\left[\sigma_{2}\left(1-v^{2}\right)-\sigma_{1}\left(v+v^{2}\right)\right] / E$

Using the same strength criterion $\varepsilon_{2}^{s}=-v \sigma_{s} / E$ we have defined the following formula (2) for compressive strength of simply deformed rock:

$$
\sigma_{s}^{p}=\frac{1-v}{v} \sigma_{x}+\frac{\sigma_{s}}{1+v}
$$

Considering the edge part of extracting seam being volumetric compressed, we derive from formula (1) the following equation defining seam's compression strength:

$$
\sigma_{s}^{v}=\frac{1-v}{v}\left(\lambda \cos ^{2} \alpha+\sin ^{2} \alpha\right) \gamma H+\sigma_{s}
$$

where $\alpha$ - the dipping angle of a seam; $\lambda$ - the rate of horizontal thrust.

For flat seam this equation has the following view:

$$
\sigma_{s}^{v}=\frac{1-v}{v} \lambda \gamma H+\sigma_{s}
$$

In a seam section paralleled to the line of coal-face work or to the drift, the seam is plainly strained, and the strength of its edge side can be defined as follows:

$$
\sigma_{s}^{p}=\frac{1-v}{v}\left(\lambda \cos ^{2} \alpha+\sin ^{2} \alpha\right) y H+\frac{\sigma_{s}}{1+v} .
$$

Durability of flat seam, which is plainly strained, can be calculated using formula (6):

$$
\sigma_{s}^{p}=\frac{1-v}{v} \lambda \gamma H+\frac{\sigma_{s}}{1+v} .
$$

In the hydro-static field of strengths, the durability of flat seam is defined using formulae (4), (6) with $\lambda=1$. For the absence of horizontal deformations in solid array of rock (according to A.N. Dinnik Hypotheses), i.e. for $\lambda=v /(1-v)$, we used simple equations for seam's durability calculations:

$$
\sigma_{s}^{v}=\gamma H+\sigma_{s}
$$

and

$$
\sigma_{s}^{p}=\gamma H+\frac{\sigma_{s}}{1+v}
$$

The obtained formulae (3) and (5) and their particular cases show that the seam strength at volume and plane-strain state depends only on the deformation $\mathrm{v}$ and strength $\sigma \mathrm{c}$ coal characteristics as well as the type and extent of seam load in accordance with the parameters $\lambda, \gamma \mathrm{H}$ and $\alpha$. On the descending branch of sample simple deformation the further sustainable cracking is occurring. We assume that the energy of elastic deformation stored in the sample is partially consumed for the above deformation (disclosure and growth of cracks), and the residual strength is small, which is typical for brittle rocks. We write down the condition of equality of deformation energies on the ascending and descending branches of the diagram of sample simple compression:

$$
w_{1}=w_{2}+w_{1}^{0}
$$

where $w_{1}^{0}$ is the residual energy of sample's elastic deformations in the above condition.

On the rising branch for simple deformation with module $E$ the accumulated energy is defined as:

$$
w_{1}=\frac{\sigma_{s}^{2}}{2 E}
$$

On the declining branch the strength dependence on the above deformations is also linear with decline module $\mathrm{M}$, and has the following view:

$$
\sigma=\sigma_{s}-\left(\varepsilon-\varepsilon_{s}\right) \cdot M
$$

The energy of the above deformation ( $\boldsymbol{W}_{\text {above }}$ ) with the value of declining strength $\sigma$ can be defined in the following way:

$$
W_{\text {above }}=\int_{\varepsilon_{s}}^{\varepsilon} \sigma(\varepsilon) d \varepsilon=\int_{\varepsilon_{s}}^{\varepsilon}\left[\sigma_{s}-\left(\varepsilon-\varepsilon_{s}\right)\right] d \varepsilon=\sigma_{s} \frac{\sigma_{s}-\sigma}{M}-\frac{\left(\sigma_{s}-\sigma\right)^{2}}{2 M} .
$$

And the residual energy of sample's elastic deformations for the same value can be defined as:

$$
w_{1}^{0}=\frac{\sigma^{2}}{2 E} \text {. }
$$

The conditions of energy equality of under- and above deforming can be defined as:

$$
\frac{\sigma_{s}^{2}}{2 E}=\sigma_{s} \frac{\sigma_{s}-\sigma}{M}-\frac{\left(\sigma_{s}-\sigma\right)^{2}}{2 M}+\frac{\sigma^{2}}{2 E},
$$

This after simplifications comes down to the following equation:

$$
\frac{\sigma_{s}^{2}}{E}-\frac{\sigma^{2}}{E}=\frac{\sigma_{s}^{2}}{M}-\frac{\sigma^{2}}{M} .
$$

From here it follows that $\mathrm{M}=\mathrm{E}$, so the decline module equals the module of simple deformation.

In case of volumetric deformation the decline module is the same and the residual durability increases in the same way as compressive strength, in particular:

$$
\sigma_{o}^{1}=\sigma_{s}^{v}-\sigma_{s}=\frac{1-v}{v} \sigma_{x}
$$

Proportional dependence of residual durability of rock under the volumetric compression on sidereal load was proved by laboratory tests for volumetric compression of coal and quartz rock $[23,24]$.

\section{CONCLUSIONS}

This article contains the results obtained by analyzing full diagram of compression and physical laws of deformation and crashing of rocks. The criterion of rock strength in volume contraction is the value in transverse deformations when reaching simple compressive strength. Rock strength at compression in volume and plain-strain compression is 
defined by the sample simple compression, its coefficient of transverse deformation and the value of the lateral load. The maximum bearing pressure is constant and equal to the value of the volume compressive strength of coal. Rocks recession module is the module of linear deformation in the pre-limit condition. The compressive strength and the residual strength of the rock are proportional to the cross-pressures. Obtained numerical expressions and deformation characteristics of rocks should be used when calculating the reference pressure on the coal seam.

\section{REFERENCES}

[1] Khoreshok A. On side cutting bit when operating at sheerer drums Ugol', 2002, vol. 7, pp. 10-11.

[2] Aksenov V.V., Khoreshok A.A. and Beglyakov V.Yu. Justification of creation of an external propulsor for multipurpose shield-type heading machine - GEO-WALKER. Applied Mechanics and Materials, 2013, vol. 379, pp. 20-23.

[3] Kovalev V., Gerike B., Khoreshok A., and Gerike P. Preventive maintenance of mining equipment based on identification of its actual technical state. Taishan Academic Forum - Project on Mine Disaster Prevention and Control, 2014, pp. 184-189.

[4] Lekontsev Yu.M., Sazhin P.V., Temiryaeva O.A., Ushakov S.Yu., Khoreshok A.A.,. Two-side sealer operation. Journal of Mining Science, 2013, 49(5), pp.757-762.

[5] Zhironkin S.A. Governmental factoring development of TEK Kuzbass. Ugol', 2001, vol. 6, pp. 62.

[6] Zhironkin S.A. Prospects and new possibilities investment attracting to Kuzbass coal mining industry. Ugol', 2002, vol. 6, pp. 31-36.

[7] Zhironkin S.A. Factoring and leasing development at coal mining industry of Kuzbass as an important element of its financial part. Ugol', 2001, vol. 4, pp. 29-30.

[8] Zhironkin S.A. About measures of vexel circulation development and vexelability definition of fuel-and-power complex' enterprises. Ugol', 2002, vol. 4, pp. 47-48.

[9] Lesin Y.V., Lukyanova S.Y., and Tyulenev M.A. Mass transfer of dispersed particles in water filtration in macro-grained media. Journal of Mining Science, 2010, 46(1), pp. 78-81.

[10] Tyulenev M.A., and Lesin Y.V. Justification complex purification technology open-pit mines wastewater. Taishan Academic Forum Project on Mine Disaster Prevention and Control, 2014, pp. 441-444.

[11] Lesin Y.V., Luk'yanova S.Y., and Tyulenev M.A. Formation of the composition and properties of dumps on the open-pit mines of Kuzbass. IOP Conference Series: Materials Science and Engineering, 2015, vol. 91 (1), 012093.

[12] Tyulenev M, Zhironkin S., and Litvin O. The low-cost technology of quarry water purifying using the artificial filters of overburden rock. Pollution Research, 2015, 34(4), pp. 825-830.

[13] Ryzhkov Y.A., Gogolin V.A., and Karpenko N.V.,. Modelling the structure of solid masses of lump and granular materials (plane problem). Journal of Mining Science, 1992, 28(1), pp. 6-12.

[14] Ryzhkov Y.A., Lesin Y.V., Gogolin V.A., Karpenko N.V. 1996. Modeling the structure of fragmented and granular material: Threedimensional problem. Journal of Mining Science, 32(3), pp. 188-191.

[15] Ivanov, K.I., and Betanely K.P. Some of the results of field studies bearing capacity and stress state of coal pillars. Ugol', 1963, No3, pp.21-23.

[16] Bieniawski, Z. T. and Denkhaus H. G. Failure of fractured rock. Int. J.Rock Mech. Min. Sci., 1969, vol.6, pp. 323 - 409.

[17] Stavrogin A.N., Tarasov B.G., Shirkes O.A., and Pevzner E.D. Strength and deformation of rocks before and after the breakdown point. Soviet Mining Science, 1981, 17(6), pp.487-493.

[18] Bieniawski Z.T. Strata control in mineral ingineering. Moscow Mir Publishers, 1990, pp. 269.

[19] Gogolin V. A., and Ryzhkov Yu. A. A nonlinear model of the interaction between the side rocks, the stowage material, and the coal seam. Soviet Mining Science, 1977, 13(1), pp.17-20.
[20] Linkov A.M. Deformation beyond the limit in the plane problem of a circular working. Soviet Mining Science, 13(5), 1977, pp. 455-460

[21] Petukhov I. M., and Linkov A. M. Mechanics of Rockbursts and Outbursts. Moscow, Nedra Publishing House, 1983pp. 280.

[22] Kornev V.M., and Zinov'ev A.A. Quasi-brittle rock failure model. Journal of Mining Science, 2013, 49(4), pp. 576-582.

[23] Ozbay, M. U., Dedet T., and Napiert A.L.J. Physical and numerical modeling of rock fracture. The Joumal of The South African Institute of Mining and Metallurgy. December, 1996, pp. 317-323.

[24] Melchers K., Kretschmann Yu., Goerke-Mallet P., Kleineberg K., and Tyulenev M. Elementy i aspekty post-ekspluatatsionnogo perioda gornykh predpriyatij [Elements and aspects of post-operational period of mining enterprizes]. Vestnik Kuzbasskogo gosudarstvennogo tehnicheskogo universiteta, 2015, vol. 6, pp. 3-13. 